\title{
Can Cycle Lanes be Justified in Jaffna Roads : A Case Study on Kalvinayakadu - Kokuvil Road (JFC006)
}

\section{K. S. Weerasekera}

\begin{abstract}
With the post-conflict development under Uthuru Wasanthaya programme the government is determined in developing and rehabilitating of Jaffna peninsula roads which have been neglected over past three decades. Funding is obtained mainly through World Bank, Asian Development Bank and other donor agencies. Although planning, designing, and construction of most of these roads are being currently carried-out, it is observed that not much priority is being given to the large cycling population existing in Jaffna peninsula.
\end{abstract}

Through this study an attempt is made to highlight the large cycling population of Jaffna, and an effort is made to investigate whether it could justify dedicated cycle lanes to be considered in the Jaffna peninsula roads, by taking Kalvinayakadu - Kokuvil road (JFC006) as a case study. The results from the study showed that a cycle-lane could be justified along this road; suggesting that road planners and designers should consider introducing dedicated cycle lanes for Jaffna peninsula roads which could offer a better service and a safety standard to the committed cycle population which is customary to the area.

Keywords: $\quad$ Bicycle Lanes, Cycle Lanes, Dedicated Cycle Lanes, Jaffna Roads.

\section{Introduction}

Cycling currently perform an important transport role within communities in many developing countries. Transport statistics in Sri Lanka in urban and rural areas show clearly that cycling is a popular and alternative mode of transport and is increasing in popularity with the ever increasing fuel prices (Weerasekera, [5]). The Uthuru Wasanthaya programme undertaken by the Sri Lankan Government to rehabilitate and improve of Northern provincial roads is currently underway. It could be seen that due to flat terrain of the area and popularity of cycles among traditional population in the Northern province, bulk of community traveling is taking place on cycles. This is evident from the recent traffic surveys conducted in Jaffna peninsula roads (Feasibility Study Report of Jaffna Provincial Roads, [2]).

Kalvinayakadu - Kokuvil road (JFC006) is located closer to Jaffna town (see Figure 1). This road passes through a populated area where the surrounding consists of residential houses and home gardens with a low level of business activity. Total length of the road is $3.22 \mathrm{kms}$ starting from Jaffna - Point Pedro road and cutting across Kopay - Nallur road around 0.5 $\mathrm{km}$, Jaffna - Palaly road at $1.6 \mathrm{~km}$, main railway line at $2.3 \mathrm{~km}$ (although this railway line is abandoned at present, the government has committed to build this soon) and road ends by connecting with Jaffna - Kankesanthurai road at $3.22 \mathrm{~km}$. This indicates that the road cuts across four main roads radiating from Jaffna town. Hence it shows the importance of the road.

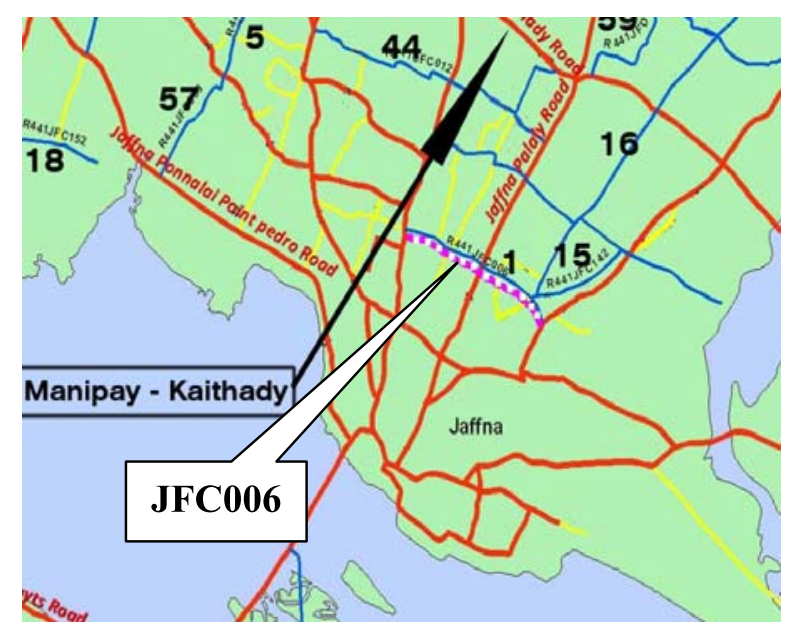

Figure 1 - Layout Plan Jaffna Roads 
A case study was conducted on Kalvinayakadu Kokuvil road (JFC006), and it was observed that a total of 2715 cycles were counted per day on two directions, compared to 3237 total motorised vehicles (bulk of the motorized traffic, 2530 are being motor cycles) counted per day on both directions (see Table 1). This heavy flow of cycles suggests the necessity of paying special attention for cycle riders.

\section{Traffic Survey}

A 24 hour manual classified traffic count was conducted on Kalvinayakadu - Kokuvil road. This classified count included counting of different categories of vehicles (including cycles) traveling both directions separately in 15 minute intervals. Total number of vehicles traveling on both directions, together with their percentages is shown in Table 1. From traffic flow data that was collected, it was found Peak Hour Flow (PHF) was taking place from 8:00 AM to 9:00 AM. Percentages of different categories of vehicular flows during peak hour are also computed and indicated in Table 1.

From Table 1 it could be noted that heavy percentage of cycles $(48.64 \%$ during peak hour and $45.61 \%$ from total flow) followed by motorcycles $(40.69 \%$ during peak hour and $42.51 \%$ from total flow) could be observed both during peak hour and out of total traffic flow that occurs during the day.

Table 1 - Vehicle Count Data on Kalvinayakadu Kokuvil Road (JFC006)

\begin{tabular}{|l|r|c|c|c|}
\hline \multicolumn{1}{|c|}{$\begin{array}{c}\text { VEHICLE } \\
\text { CATEGORY }\end{array}$} & ADT & $\begin{array}{c}\text { \% } \\
\text { ADT }\end{array}$ & PHF & $\begin{array}{c}\text { PH } \\
\text { PHF }\end{array}$ \\
\hline Motorcycle & 2530 & $42.51 \%$ & 225 & $40.69 \%$ \\
\hline Three-wheeler & 291 & $4.89 \%$ & 23 & $4.16 \%$ \\
\hline $\begin{array}{l}\text { Car / Jeep / 4x4 / } \\
\text { Double Cab / Van }\end{array}$ & 153 & $2.57 \%$ & 16 & $2.89 \%$ \\
\hline $\begin{array}{l}\text { Passenger Van Duel } \\
\text { Purpose Van }\end{array}$ & 83 & $1.39 \%$ & 4 & $0.72 \%$ \\
\hline Light Goods Vehicles & 32 & $0.54 \%$ & 4 & $0.72 \%$ \\
\hline $\begin{array}{l}\text { Medium Goods } \\
\text { Vehicles }\end{array}$ & 37 & $0.62 \%$ & 3 & $0.54 \%$ \\
\hline Heavy Goods Vehicles & 46 & $0.77 \%$ & 3 & $0.54 \%$ \\
\hline $\begin{array}{l}\text { Heavy Goods Vehicles } \\
\text { with Multi axles }\end{array}$ & 5 & $0.08 \%$ & 0 & $0.00 \%$ \\
\hline Medium Bus & 8 & $0.13 \%$ & 1 & $0.18 \%$ \\
\hline Large Bus & 6 & $0.10 \%$ & 2 & $0.36 \%$ \\
\hline Tractor & 46 & $0.77 \%$ & 3 & $0.54 \%$ \\
\hline Cycle & $\mathbf{5 9 5 2}$ & $\mathbf{1 0 0 . 0 0}$ & $\mathbf{5 5 3}$ & $\mathbf{1 0 0 . 0 0}$ \\
\hline $\begin{array}{l}\text { TOT } \\
\text { TOT }\end{array}$ & & & & \\
\hline
\end{tabular}

Fig. 2 \& 3 below indicate the Average Daily Traffic (ADT) flows and Peak Hour Flows (PHF) of four main categories of traffic along Kalvinayakadu Kokuvil road (Cycles, Motorcycles, Three-wheelers \& 4 or more wheel motorized vehicles).

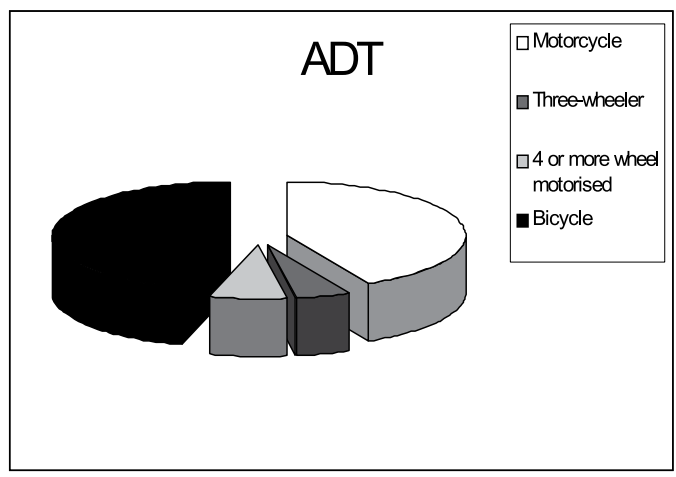

Figure 2 - Average Daily Traffic Flows (ADT)

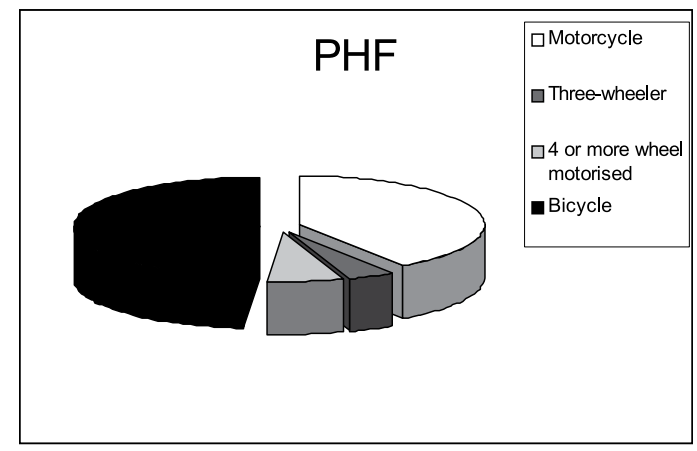

Figure 3 - Peak Hour Flows (PHF)

During the traffic survey, the enumerators observed and recorded the number of passengers traveled in each vehicle. From this passenger count information the average number of passengers traveling in each category of vehicles was computed (see Table 2).

Information regarding carriageway width, shoulder width, and available road reservation were also obtained. Since the available average carriageway width is around 4.5 meters and terrain is flat and no critical curves or bends are involved along the road, the general alignment of the road is satisfactory.

Table 2 indicates the average number of passengers that were traveling under each category of vehicles, and Passenger Car Units (PCU) of different vehicle categories. 
Table 2 - Average Number of Passengers in Different Types of Vehicle Categories

\begin{tabular}{|l|c|c|}
\hline VEHICLE CATEGORY & $\begin{array}{c}\text { Av. No. } \\
\text { of Pass. }\end{array}$ & PCU \\
\hline Motorcycle & 1.5 & 0.4 \\
\hline Three-wheeler & 3.2 & 0.8 \\
\hline $\begin{array}{l}\text { Car/Jeep/4x4/Double } \\
\text { Cab/Van }\end{array}$ & 2.1 & 1.5 \\
\hline $\begin{array}{l}\text { Passenger Van Duel } \\
\text { Purpose Van }\end{array}$ & 6.5 & 1.8 \\
\hline Light Goods Vehicles & - & 1.8 \\
\hline Medium Goods Vehicles & 2.5 & 2.0 \\
\hline Heavy Goods Vehicles & 2.5 & 2.5 \\
\hline $\begin{array}{l}\text { Heavy Goods Vehicles } \\
\text { with Multi axles }\end{array}$ & 2.7 & 3.8 \\
\hline Medium Bus & 26 & 2.0 \\
\hline Large Bus & 48 & 2.5 \\
\hline Tractor & 1.2 & 3.8 \\
\hline Cycle & 1.1 & 0.7 \\
\hline
\end{tabular}

(Source:: PCU factors based on Transportation Engineering Division, University of Moratuwa)

\section{Methodology}

The total numbers of passengers carried by each category of vehicles were computed separately for different categories of vehicles, per day, and during peak hour, are tabulated in Table 3 . These values were computed by using the average number of passengers that were traveling under each category of vehicles indicated in Table 2.

Table 3 - Passengers Carried by Different Category of Vehicles

\begin{tabular}{|l|r|r|}
\hline VEHICLE CATEGORY & Pass/day & Pass/PH \\
\hline Motorcycle & 3795 & 338 \\
\hline Three-wheeler & 728 & 58 \\
\hline $\begin{array}{l}\text { Car/Jeep/4x4/Double } \\
\text { Cab/Van }\end{array}$ & 321 & 34 \\
\hline $\begin{array}{l}\text { Passenger Van Duel } \\
\text { Purpose Van }\end{array}$ & 457 & 22 \\
\hline Light Goods Vehicles & 64 & 8 \\
\hline Medium Goods Vehicles & 93 & 8 \\
\hline Heavy Goods Vehicles & 115 & 8 \\
\hline $\begin{array}{l}\text { Heavy Goods Vehicles } \\
\text { with Multi axles }\end{array}$ & 14 & 0 \\
\hline Medium Bus & 200 & 25 \\
\hline Large Bus & 288 & 96 \\
\hline Tractor & 69 & 5 \\
\hline Cycle & 3258 & 323 \\
\hline TOTAL (MOTORISED) & $\mathbf{6 1 4 2}$ & $\mathbf{5 9 9}$ \\
\hline TOTAL & $\mathbf{9 4 0 0}$ & $\mathbf{9 2 2}$ \\
\hline
\end{tabular}

\section{Analysis \& Results}

Computation:

(a) Percentage of passenger movement on a cycle per day $\left[C_{A D T}\right]$

$C_{1} \quad$ - No. of passengers traveled on cycle per day

$\sum M_{1}$ - Total number of passengers traveled through motorized vehicles (including motorcycles)

$C_{1}=3258, \quad \sum M_{1}=(9400-3258)=6142$

$C_{A D T}=\frac{C_{1}}{\sum M_{1}} \times 100=\frac{3258}{6142} \times 100=53 \%$

(b) Percentage of passenger movement on cycle during peak hour (8:00AM to 9:00AM) [ $\left.C_{P H}\right]$

$C_{2}$ - No. of passengers traveled on cycle during peak hour

$\sum M_{2}$ - Total number of passengers traveled through motorized vehicles (including motorcycles) during peak hour

$C_{2}=323, \quad \sum M_{2}=(922-323)=599$

$C_{P H}=\frac{C_{2}}{\sum M_{2}} \times 100=\frac{323}{599} \times 100=54 \%$

Hence it could be seen that percentage of passenger movement on cycles is well over $50 \%$ in both (a) throughout the day, and (b) during peak hour.

\section{Reference to Literature}

As per Road Users' Handbook [3], for a cycle lane to be justified the number of cycle riders in a priority lane should at least more than $1 / 3$ of the total number of all motorized occupants in the adjacent lane. AUSTROADS guideline for cycles [1] also mention when $20 \%$ of the population regularly use cycles in their 
transportation, it is therefore suggested that, planners, designers and managers give thought for dedicated cycle lanes.

Planning for cyclists should occur at many different levels from the development of broad policies and strategies to relatively small local projects. It involves a commitment from all levels of government and input from the general public, and local cycle groups. The main goal of cycle lane planning is to encourage cycling as a desirable alternative form of transport and to provide community and government programmes which will provide for safe and convenient travel by cycle whilst maintaining a satisfactory level of service for all other road users.

Following factors influence the generation of cycle trips (Werasekera [5]) :

- types of community in the area and extent of cycle usage.

- availability of facilities.

- topographical factors (terrain, distance)

- weather and climatic conditions.

- existing traffic regulations.

- other available transport systems.

\section{Conclusions}

In this case study, an attempt was made to look at the large cycling population of Jaffna, and an effort was made to investigate whether dedicated cycle lanes could be considered for Jaffna peninsula roads.

It is clear that results from Table 3, that more than $1 / 3$ passenger movement during peak hour, as well as total passenger movement during the day is taking place on cycles. Hence it is the prime responsibility of the road planners to ensure the safety of this large proportion of passenger movement along the road during the peak hours as well as through out the day.

The results from the study showed that a cyclelane could be justified along Kalvinayakadu Kokuvil road; suggesting that road planners and designers should consider introducing dedicated cycle lanes for Jaffna peninsula roads which could offer a better service to the committed cycle population which is customary to the area.
It also could be concluded that from recent traffic counts conducted for feasibility study of Jaffna District Provincial Roads [2], for Ministry of Local Government \& Provincial Councils, Sri Lanka, a heavy percentage of cycle trips are taking place both during peak hours and throughout the day, in many of the provincial roads in Jaffna peninsula (especially closer to Jaffna town). Hence it will be interesting to closely examine whether those roads too qualify for cycle dedicated lanes and come up with suitable solutions by the road planners and designers.

\section{Acknowledgements}

Author wishes to acknowledge Mr. S. Kokulkanth, and Mr. Max Blacker of CARDNO International Pty Ltd for providing necessary information, and assistance to conduct this study.

\section{References}

1. AUSTROADS, Guide to Traffic Engineering Practice, Pt 14 - Bicycles, Roads and Traffic Authority, NSW, Australia, 1991.

2. Feasibility study of Jaffna District Provincial Roads, Ministry of Local Government \& Provincial Councils, Sri Lanka, June 2010.

3. Road Users' Handbook, Roads and Traffic Authority, NSW, Australia, 1992.

4. Transportation Engineering Division, University of Moratuwa, 2006.

5. Weerasekera, K. S., Towards Better Roads, P \& P Associate, Colombo, Sri Lanka, 2008. 